Original Research Paper

\title{
The Reliability of Routing Protocols as an Important Factor for Road Safety Applications in VANET-based Autonomous Cars
}

\author{
Ananto Tri Sasongko, Grafika Jati, Bob Hardian and Wisnu Jatmiko \\ Department of Computer Science, Universitas Indonesia, Indonesia
}

\author{
Article history \\ Received: $10-02-2020$ \\ Revised: 05-05-2020 \\ Accepted: 12-06-2020 \\ Corresponding Author: \\ Ananto Tri Sasongko \\ Department of Computer \\ Science, Universitas Indonesia, \\ Indonesia \\ Email: ananto.tri@ui.ac.id
}

\begin{abstract}
The autonomous cars are considered as a tremendous disruptive innovation in the coming years. They enable a driving automation system to replace human drivers to control the vehicle with better recognition, decision and driving skills and ultimately enhance the road users' experience and traffic safety. They can communicate with other cars as they are ready with the Vehicle to Vehicle (V2V) communication technology based on Vehicular Ad hoc Networks (VANETs). One of the objectives of $\mathrm{V} 2 \mathrm{~V}$ communication is for the safety of all road users. Adequate reliability of routing protocol is subject of concern and must be taken into account to reach an immense standard of road safety accurately and timely. Having no reliability the critical road safety messages will be useless; consequently, the accident that might happen is unable to prevent or avoid. The purpose of this research is to investigate and analyze the quantitative measure of reliability. The reliabilities of a reactive single-path AODV and a multipath AOMDV routing protocols that comply with road safety requirements in various traffic conditions are studied. The traffic conditions that may impact the internetworking of autonomous cars include node density, size of road area and speed of the nodes. The methods used in this study are based on simulations by using Network Simulator version-2 (NS2) as a network simulator and Simulation of Urban Mobility (SUMO) as a mobility simulator. The simulation results show that both routing protocols, a single-path AODV and a multi-path AOMDV, satisfy the road safety requirements in some conditions. AODV is better in packet delivery, whereas AOMDV has a better performance on average end to end delay. This study is expected to contribute to the determination of the appropriate protocol for use in road safety applications under certain traffic conditions. In conclusion, the reliability of routing protocol is an essential factor to consider in the operation of VANET-based autonomous cars so that the safety and comfort of road users can be guaranteed.
\end{abstract}

Keywords: Reliability, Routing Protocol, Road Safety Applications, VANETs, Autonomous Cars

\section{Introduction}

Recently, autonomous cars hit the news and domineered tech discussions. They are already rejuvenating and their development has even been credited with bringing about the revolution of transportation. The progress of information and communication technologies, as well as the evolving of modern cars, offers the characteristics and aspects for the construction of smart vehicles. These smart cars support functions such as detecting the environment, making decisions quickly and in time, traveling without any human interaction, retaining stable mobility habits and executing all manner of maneuvers and maintaining constant speed automatically. Those vehicles are classified as autonomous cars, also called driverless or self-driving cars (Hussain and Zeadally, 2019).

The driverless car emersion is the outcome of excellent studies from wireless communication, embedded systems, guiding along route, sensor and ad hoc network technologies, data collection, distribution and analysis. Autonomous cars leverage the concept of 
connected car technology and they employ a Vehicular Ad-hoc Network (VANET) technology. Cars can communicate with each other via the regular Dedicated Short-Range Communication (DSRC) protocol when within the contact range (Salvo et al., 2015).

In VANETs, a routing protocol has a vital role in delivering messages from a source node to the destination nodes. It's responsible for making sure that the messages arrive at the targeted destination by traveling through intermediate nodes hop-by-hop accurately and timely (Bello-Salau et al., 2019).

Based on the number of paths, routing protocols are categorized into two groups: single-path and multi-path routing protocols. A single-path routing protocol has one path, whereas a multi-path routing protocol has two or more paths in their routes from the source node to the destination node. Since a single-path routing protocol has only one path when the link is broken, it needs to reinitiate the routing process. On the other hand, a multi-path routing protocol can utilize different paths in case broken links happened without reinitiating the routing process.

Under the strategy of route discovery, routing protocols are divided into proactive, reactive and hybrid (Yang and Liu, 2019). Proactive routing protocols maintain a routing table in all nodes that contain routing information from a node to other nodes. Reactive routing protocols create a route, particularly if the origin node needs to communicate. They don't have to keep the routing information of all nodes in real-time, like a tabledriven routing protocol. The hybrid routing protocol uses both active routing and on-demand routing. It splits up the network into domains and utilizes active routing and reactive routing policies within and between domains.

In this study, we will apply reactive single-path and multi-path routing protocols, which are Ad hoc Ondemand Distance Vector (AODV) (Perkins and Royer, 1999) represents a single-path and Ad hoc On-demand Multi-path Distance Vector (AOMDV) (Marina and Das, 2006) represents a multi-path. Reactive routing protocols are chosen since the nodes as the members of the network are unknown; furthermore, they are more applicable and realistic in this kind of environment.

VANETs technology supports two broad categories of applications according to their primary purpose into non-safety (comfort, entertainment) applications and safety-related applications (Peng et al., 2019). Comfort applications are also referred to as non-safety apps, which aim to improve comfort levels for drivers and passengers by rendering the ride more comfortable and increasing traffic performance. Applications for safety use wireless communication between vehicles, or between vehicles and infrastructure to improve road safety and prevent accidents. Arif et al. (2019) use the terms secure and non-secure instead of safety and nonsafety applications in their paper. A wide range of secure and non-secure applications hires VANETs to facilitate appreciation including, for example, automobile well-being, scheduled toll collection, enhanced route, executive flow, area-based governments, locating the nearest convenience store, restaurant or tourist attraction and entertainment apps.

For several decades, severe measures for road safety have been taken into consideration by transportation stakeholders. When designing safety applications, we must profoundly take into account the constraints and requirements for the sake of the high quality of service. The most crucial needs of these applications are decent reliability, high ratio of packet delivery and low end-to-end delay. To fulfill these strict requisites in a vehicular network system, VANETs routing protocols must comply with the standard of road safety applications and make sure that the critical safety messages will be delivered on time and intact; otherwise, it will be useless.

In this study, the reliability of routing protocols of road safety services becomes our primary focus. Having no reliability, the crucial messages of the road safety applications will be useless; consequently, the incidence might be happened and unavoidable or fail to prevent. Nonetheless, the intrinsic natures of VANETs, such as fast vehicle mobility and frequent link breakage, hinder the necessities of the safety described above services. Therefore, the reliability of routing protocols is necessary and becomes an essential factor for road safety applications in interconnected autonomous cars based on VANETs' technology.

This paper is structured as follows: First, we present VANET-based Autonomous Cars. Next, we introduce the different on-demand routing protocols based on the number of paths. Then, we offer road safety and its reliability on autonomous cars. Next, we present the mobility models in the simulation. After that, we detail performance evaluations used to measure the routing protocols in various conditions. Then, we present simulation results and analysis. Finally, we conclude with a conclusion.

\section{VANET-Based Autonomous Cars}

\section{Autonomous Car Technologies}

The autonomous car has been given considerable interest during the past decade and various institutions have developed prototype versions. However, the realization of autonomous vehicles remains a significant challenge. An autonomous car also referred to as a driverless car, robotic car or self-driving machine, is an automobile that has an autopilot system that allows it to travel safely from one location to another without a human driver's assistance. A human being's only role in such a vehicle would be to state the destination (Zekri and Jia, 2018). For the autonomous car to operate in a full range of environments with millions of encumbering factors, it requires Artificial Intelligent (AI) to be 
accounted for. AI can permit the development and testing of the software at the base level with a selflearning capability. Using a driverless car instead of a conventional automobile will offer various potential advantages. Driverless vehicles may contribute to several changes in transport systems, such as a significant reduction in traffic accidents, a substantial increase in road capacity and more well-organized transport. Therefore, traffic police or even road signage would be less needed and also an increased ability to deal with traffic movement.

The fundamental physical components of autonomous cars, depicted in Fig. 1 (Kuhr, 2017), are as follows: (1) Camera: It provides real-time obstacle detection of facilitate lane departure and track roadway information, (2) Radio Detection and Ranging (RADAR): It detects short and long-range depth, also the presence of an object at a certain distance and usually something that moves like a vehicle, (3) Light Detection and Ranging (LIDAR): It measures distance by illuminating target with pulsed laser light and measuring reflected pulses with sensors to create 3D map of area in more discrete and densely-spaced increments, (4) Global Positioning System (GPS): It triangulates position of car using satellites becomes the critical link for autonomous car to determine their location as they move, (5) Sensors: Odometry for monitoring vehicle distance travel and speed, whereas Ultrasonic for calculating distance using high-frequency sound waves and bounces-back, (6) Central Processing
Unit (CPU): The "Brain" of the system is in charge of receiving and processing information from various components to direct the vehicle, (7) Dedicated Short Range Communication (DSRC): It is the communication device allowing vehicle to communicate with other Vehicles (V2V) and Infrastructures (V2I). DSRC is a standard of wireless communication that enables reliable data transmission for active safety applications in VANETs.

\section{Vehicular Ad-hoc Networks}

Vehicular Ad hoc Networks (VANETs) are wireless vehicle-based communication networks established without infrastructures (ad hoc). The vehicles function as communication and relay nodes and then they form dynamic networks on the roads. Vehicles on the road communicate with other vehicles by using Vehicle to Vehicle (V2V) type of communications. They can communicate with a particular infrastructure called a Road Side Unit (RSU) using the method called Vehicle to Infrastructure (V2I) communication (Darwish et al., 2018). To be able to communicate, the vehicle must have a wireless network device called On-Board Units (OBU) installed on the vehicle that functions as a transceiver as well as a router. Communications between these devices on the vehicles use the standard known as IEEE 802.11p and also Dedicated Short Range Communication (DSRC). DSRC is used as a communication means in road safety applications and entertainment applications as well.

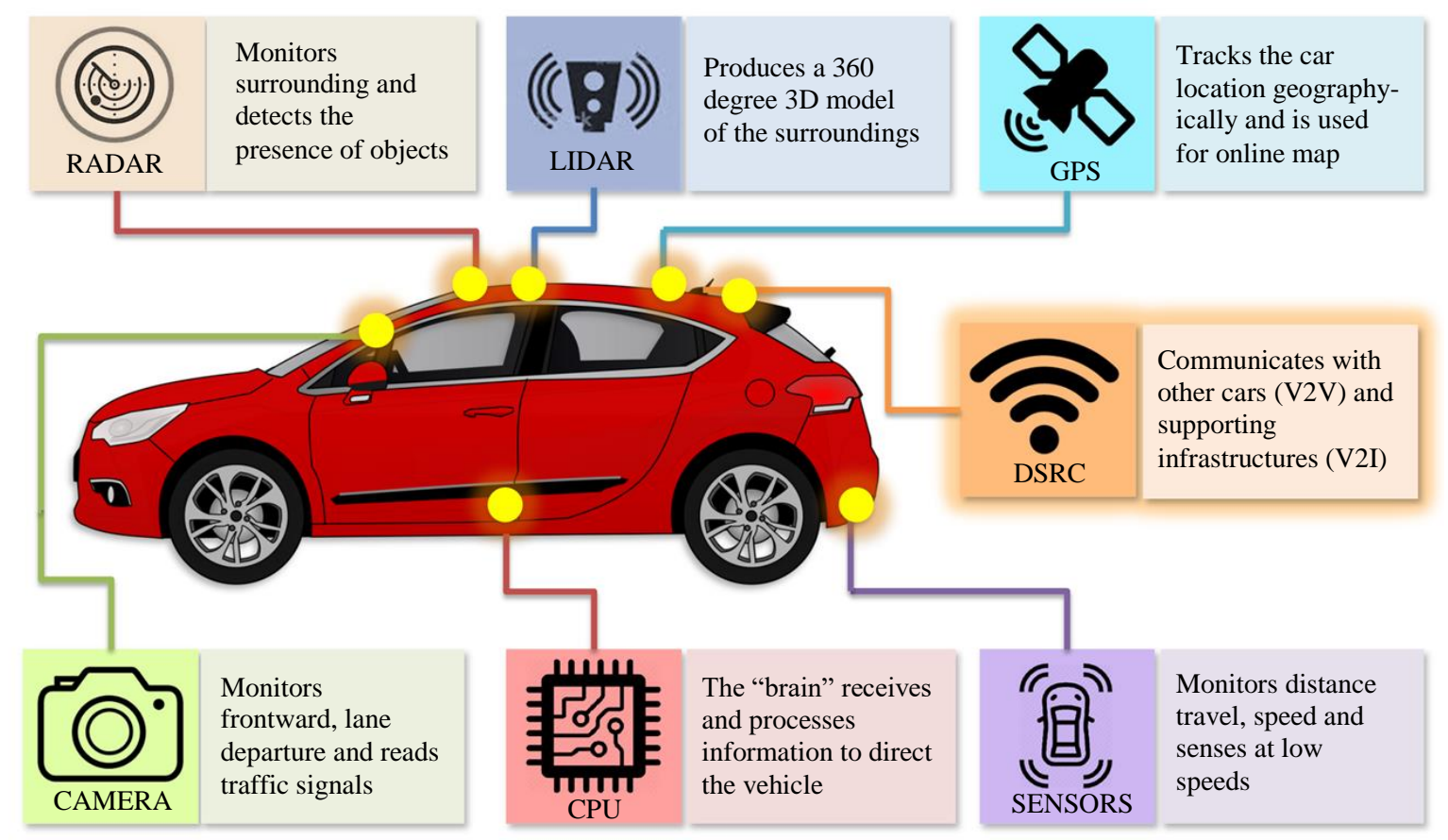

Fig. 1: Autonomous car technology 


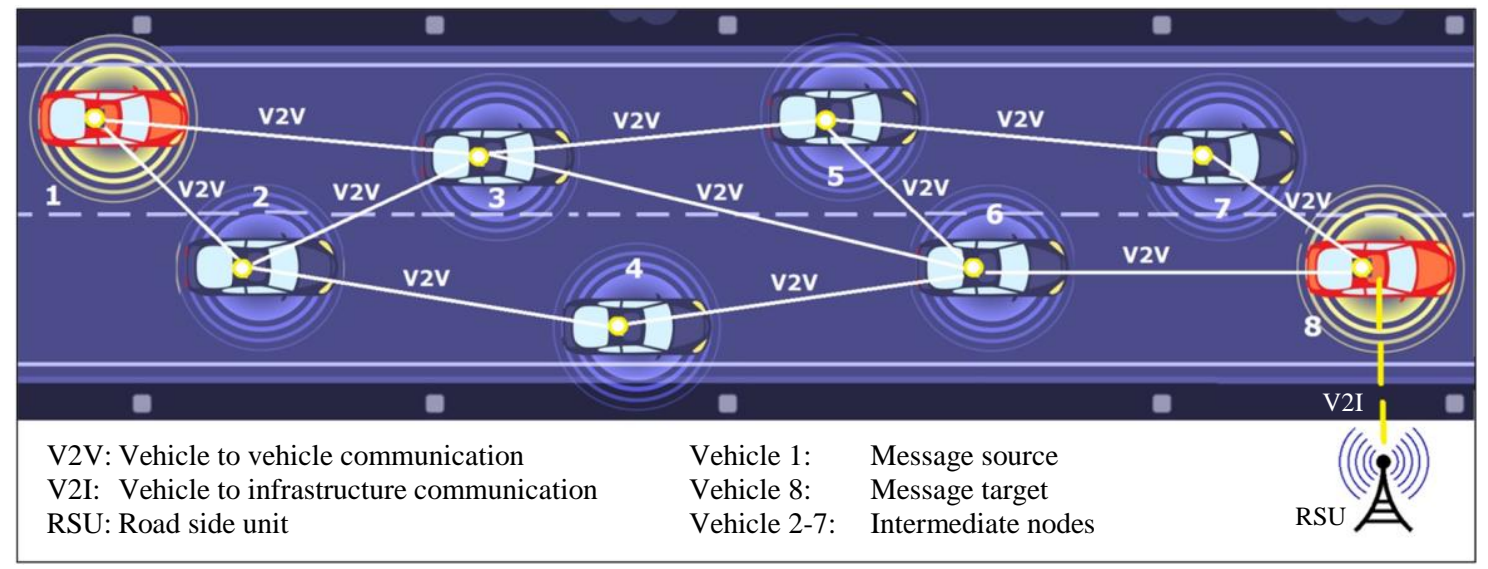

Fig. 2: VANETs architecture

Figure 2 represents the VANETs architecture, where vehicle 1 acts as a message source; vehicle 2 to 7 act as intermediate nodes and vehicle 8 acts as a message target. The RSU functions as a fixed infrastructure alongside the highway to offer user access and information services by communicating with the vehicles by using a V2I type of communication. A message sent from source to target using hop by hop (multi-hop) mechanism. It means that if there is no direct communication between the sender and the target, the message will be pass through the closest nodes to the next nodes via intermediate nodes until it arrives at the target node by using a V2V communication type.

\section{Routing Protocol}

In any topology of computer networks, including vehicular ad hoc networks, a routing protocol plays an important role. It's fully accountable to ensure that the messages are disseminated from a source node to the destination nodes hop-by-hop via intermediate nodes meticulously and punctually.

Routing protocols based on the strategy of route discovery are classified into three categories, namely, proactive, reactive and hybrid (Aravindhan and Dhas, 2019). Proactive routing protocols try to keep routing details consistent and modified from each node to any other node in the network. But, merely proactive schemes are not appropriate for reconfigurable wireless ad hoc network environment. They continuously use a large portion of the network capacity to keep the routing information up-to-date. Reactive routing protocols create routes merely if needed by the sender node. If a node wants a route to a target node, a route discovery process is initiated within the network. This process is completed once a route is found, or all possible route permutations have been examined. Hybrid routing protocols use both proactive routing and reactive routing.

Another classification of routing protocols is based on the number of paths. The single-path and multi-path routing protocols belong to this category. A single-path routing protocol owns only one path and a multi-path routing protocol possesses more than one path in the routes from the origin node to the target node (Sathya Narayanan and Joice, 2019). In this study, we are going to examine two routing protocols as follows: (a) Ad-hoc OnDemand Distance Vector (AODV) represents a reactive single-path and (b) Ad-hoc On-demand Multi-path Distance Vector (AOMDV) represents a reactive multi-path.

AODV is a reactive single-path routing protocol utilized in VANETs. The paths are determined when requested. AODV creates a single path from a sender node to a destination node and employs four messages in the routing system: Route Request (RREQ), Route Reply (RREP), Route Error (RERR) and Route Reply (RREP). AOMDV is a reactive multi-path routing protocol and an extension of AODV. It discovers multiple paths between the sender node and the target node. Compared to AODV, AOMDV eliminates packet failure and delays as well as increases the route discovery process.

\section{Road Safety Applications}

\section{Road Safety Definition}

Road safety application is an application used to prevent road users from accidents and severe injury or even death, also to act toward saving the life of road users when vehicle collision or crash occurred. The emerging of vehicular ad hoc networks has encouraged researchers to explore how such communications could be exploited to improve driver and passenger safety. In the past few years, the collaboration of government institutions with automotive industries is established to design and prototype different kinds of safety-related vehicular applications. The ultimate goal of safety applications in VANETs is to avoid and decrease the number of road accidents. This application category is sensitive to the delay so that vehicle-to-vehicle communication is employed to minimize the delay (Cunha et al., 2016). 
Table 1: Road safety application requirements

\begin{tabular}{lcc}
\hline Road safety applications & $\begin{array}{l}\text { PDR } \\
(\%)\end{array}$ & $\begin{array}{l}\text { EED } \\
(\mathrm{ms})\end{array}$ \\
\hline Pre-crash sensing & $>99$ & $<100$ \\
Cooperative platooning & $>99$ & $<100$ \\
Cooperative forward collision warning & $>95$ & $<100$ \\
Wrong way driving & $>95$ & $<100$ \\
Approaching emergency vehicle warning & $>95$ & $<200$ \\
Slow vehicle warning & $>95$ & $<400$ \\
Post-crash warning & $>95$ & $<400$ \\
Traffic jam ahead warning & $>95$ & $<400$ \\
\hline
\end{tabular}

Road safety applications using V2V or V2I communication can be categorized into five groups as follows (Al-Sultan et al., 2014): (1) Intersection collision avoidance, (2) Public Safety, (3) Sign extension, (4) Vehicle diagnostics and maintenance, (5) Information from other vehicles.

\section{Road Safety Requirements}

For safety messages to become useful, the requirements of road safety applications must be met. Safety messages have to be dispatched with up-to-the-minute, real-time delivery as they are relevant for a specific period so that the messages be genuinely worthwhile. They must reach the intended recipients with bounded delay and high packet reception rates. For safety-of-life emergency conditions, road safety messages requisite to have a maximum latency requirement of $100 \mathrm{~ms}$ (milliseconds) and high certainty that the message arrived at its destination with a minimum packet delivery ratio of 99\% (Sahoo et al., 2013).

A reliable routing protocol mechanism and algorithm are needed to overcome the problem and handle various disturbances to meet the requirements of road safety applications. In some scenarios, a driver must take action by making a rapid decision to evade a crash. Due to this reason, this type of application has severe restrictions for delay and reliability.

Table 1 presents the requirements of some road safety applications (Popescu-Zeletin et al., 2010). The requirements are based on metrics, namely the Packet Delivery Ratio (PDR) and End to End Delay (EED). The transmission type used in the requirement mostly is Vehicle-to-Vehicle communication (V2V).

\section{Mobility Models}

Cars don't move around freely. These are subject to mobility regulations, which are dictated by road topology, traffic signs, motions of other cars and physics laws that restrict the vehicle's travel according to specific acceleration and deceleration values. Such rules and restrictions have made an excellent effort for researchers to create detailed models of mobility that capture their essence, intending to create the most accurate vehicle motions in simulations (Ros et al., 2014).
There are two main ways to describe the motions of cars, including macroscopic and microscopic models of traffic flows. The macroscopic approach views the flow of traffic as continuous physical fluid flow. The microscopic approach, instead, describes the movement of each vehicle (Abdel-Halim and Fahmy, 2018).

\section{Macroscopic Mobility Model}

A macroscopic model abstracts the individual movements and models the parameters relevant to the system being evaluated. A typical example of this is the impact of the movement on a specific region. A macroscopic model is appropriate if abstract metrics sufficiently model the effects of the movements on the communication system.

\section{Microscopic Mobility Model}

The movements of individual nodes are described by a microscopic model. The location, velocity and acceleration of the individual nodes are typically modeled over time. If the motions of the individual nodes have a definitive effect on the communication system, a microscopic model is required. Recently, there has been excessive analysis of communication systems, which at least include multi-hop components. Microscopic models are responsible for modeling the position, speed and acceleration of each vehicle involved in the simulation scenario.

In this article, we concentrate on each vehicle's actions as an autonomous entity. Therefore, we limit our study of microscopic models. One of the microscopic models is the car-following model. This model is liable for regulating vehicle motion, paying attention to the car in front of it, moving in the same lane and direction, and changing lanes. By comparison to other simplified methods such as stochastic and traffic steam simulations, these models have been shown to mimic real-world vehicular dynamics. The use of functional models by simulation is of influential significance because it has a high impact on the underlying topology of the network. In fact, car-to-car interactions, as observed by carfollowing simulations, significantly affect networking metrics (Ros et al., 2014).

\section{Performance Evaluations}

A packet is a piece of data that is sent over a network from one computer to another. Packets are used because they divide large amounts of data into smaller chunks, moving over a network more accessible. A packet contains information such as source, destination, data and size to accommodate a large file arriving at the correct location and being reassembled once it gets there appropriately. Yet packet traveling is far from flawless and anything can go wrong. Improper circumstances allow the packets to transform into errors, losses and drops. 
An error in a packet means something is wrong with the packet. Two types of packet errors typically occur are (a) Transmission errors, where a packet is damaged on its way to its destination and (b) Format errors, where the format of a packet is not what the receiving device was expecting. Packets can quickly become damaged on their way through a network. Wireless devices are also suffered from packet errors caused by multiple sources of high radio frequency interference. Thus packets that travel wirelessly will easily get impaired.

A packet loss happens when one or more packet cannot reach their destination because of some issues such as link congestion, device performance, the weak signal between devices, software bugs and faulty hardware. It occurs before a packet reaches its destination, which means it can happen anywhere in a network. A packet loss is a factor that affects the packet delivery ratio.

A packet drop happens when a transmitted packet has an error in transmission or configuration, or when the transmitting system doesn't have enough storage space. When wireless devices suffer a high number of packet drops, it may be caused by the target nodes they try to connect are too far away from it. While some packet drops are unavoidable, undue packet drops can be caused by some issues, including (a) misconfigured network devices, (b) full bandwidth on the ports, (c) overload CPU or memory and (d) unreachable destinations. Packet Drop is typically discarding packets on different layers after processing packets, and packet drop is one of the reasons for data loss in some conditions. Packet drops arise due to adverse network conditions; as a consequence, the packet is discarded by the receiver or sender. A packet drop is an aspect that impacts reliability.

\section{Quantity of Service}

Quantity of Service used to evaluate the performance of VANETs consists of two metrics: (1) Packet Delivery Ratio (PDR) and (2) End to End Delay (EED).

PDR is computed as the ratio between the number of received packets and the transmitted packets at the application layer. A packet received is equal to a packet sent minus packet loss. A packet loss occurs when one or more packet cannot reach their destination. As the packet delivery ratio is inversely proportional to packet loss, we can infer that by the packet loss increases, the PDR will decrease and vice versa. In other words, the more increase in packet delivery ratio means that the routing protocol is more efficient. PDR is expressed as formula (1) (Houmer and Hasnaoui, 2019).

EED is the time it takes between the transmission of the packets and the reception of the packets. The average EED is calculated as the total time of EED divided by the total connections of the senders and the destinations of the packets. A lower average End-to-End Delay presents better performance. Average EED is expressed as formula (2) (Houmer and Hasnaoui, 2019):

$$
\begin{aligned}
& P D R=\frac{\sum_{1}^{m} P_{R}}{\sum_{1}^{n} P_{S}} \times 100 \% \\
& A v g E E D=\frac{\sum_{1}^{n}\left(P_{\text {Rtime }}-P_{\text {Stime }}\right)}{\sum_{1}^{n} P_{R}}
\end{aligned}
$$

Where:

$P_{R}=$ Packet received

$P_{S}=$ Packet sent

\section{Quality of Service}

Quality of Service is the measurement of the overall performance of a service to guarantee a certain level of accomplishment. It is affected by various technical factors; one of them is reliability. In this study, we focus on reliability as the parameter to measure the routing protocol performance of vehicular ad hoc networks for road safety applications.

According to Sattar et al. (2018), reliability is the probability of successful delivery of safety/emergency messages to all intended destinations. It is theoretically defined as the establishment of a successful connection among the defined node pairs.

Saajid et al. (2019) said that reliability is defined as the probability of the successful delivery of a message to its meant destination before the expiry of the lifetime of the message. It is also important to note that the reliability of a safety message delivery should not be less than 0.99 (Saajid et al., 2019).

Reliability is an attribute of the device, represented by the possibility that it will perform the prescribed role for a specified time under given conditions. In a qualitative context, reliability can also be described as the item's ability to remain functional. In quantitative words, reliability determines the likelihood of no operating disruption during a specified time (Birolini, 2017).

In determining the reliability in this study, the actual measurement is conducted by counting received packets $r$ and sent packets $s$ at the data link (MAC) layer. The ratio $\mathrm{r} / \mathrm{s}$ is an assessment point of the reliability. To avoid an uninformative assessment point, the $95 \%$ binomial proportion confidence interval for the reliability is employed since it is a more informative assessment (Herlich et al., 2017). A binomial proportion confidence interval is a confidence interval for the likelihood of success calculated from a series of successfailure experiments resulting from it. It determines a confidence interval for the success of a repeated experiment with only two outcomes, which are success and failure (Brown et al., 2001).

In our case, these two outcomes are "packets received" and "packet not received" at the MAC layer. There are multiple ways to calculate such a binomial proportion confidence interval, but it is necessary to 
select a way that holds for asymmetric proportions. Because the reliability we will analyze is mostly close to 1, we use the Clopper-Pearson method. For example, from 10000 sent packets, a total of 9990 were received. That results in a $95 \%$ confidence interval of [0.998161735; 0.999520360].

Clopper-Pearson interval can be written using $\mathrm{F}$ quantiles because the beta distribution is related to the Fdistribution. Mathematically, the formulation of the Clopper-Pearson interval (Franco et al., 2019) (Agresti and Coull, 1998) is shown in formula (3) and (4). Where $p_{L}$ is the lower bound, $p_{U}$ is the upper bound, $x$ is the number of successes and $n$ is the number of trials. $F(a, b, c)$ is the $1-c$ quantile from an F-distribution with $a$ and $b$ degrees of freedom:

$$
\begin{aligned}
& p_{L}>\left(1+\frac{n-x+1}{x F_{2 x, 2(n-x+1), 1-\alpha / 2}}\right)^{-1} \\
& p_{U}<\left(1+\frac{n-x}{(x+1) F_{2(x+1), 2(n-x), \alpha / 2}}\right)^{-1}
\end{aligned}
$$

Where:

$p_{L}=$ Lower bound

$p_{U}=$ Upper bound

\section{Research Methodology}

Many autonomous car simulation experiments are conducted on concept vehicles with all the crucial functionalities that are necessary for autonomous cars, with test drivers behind the wheel. Reasonable efforts were made, however, to test the performance of autonomous vehicles utilizing validated simulator tools. The software models various aspects of autonomous cars, including complexities of movement, track monitoring, fuel economy, track preparation, coordination within and between automobiles, etc. (Hussain and Zeadally, 2019). The research methodology for this study is presented in Fig. 3. We conducted the work based on simulation. The methodology consists of four steps as follows. Step 1, creating the scenarios of the vehicle mobility model including the road infrastructures. Step 2, generating the node mobility appropriate for NS2. Step 3, configuring network parameters and routing protocols then running the NS2 network simulation. Step 4, analyzing the trace file as a result of simulation in terms of Reliability, PDR and EED.

\section{Simulation Tools}

Software tools used in the simulation are Network Simulator version-2 (NS2) and Simulation of Urban Mobility (SUMO). NS2 takes a role as a network simulator and SUMO as a mobility simulator.

\section{Simulation Parameters}

Parameters used in this simulation are presented in Table 2.

\section{Simulation Scenarios}

In this research, we undergo the simulation under some parameters such as the size of the road, number of vehicles and the speed of vehicles. The road is a onedirectional highway segment of $5000 \mathrm{~m}(5 \mathrm{~km})$ in length with four lanes around $50 \mathrm{~m}$ in width. Traffic density expresses the degree of the congestion of vehicles on the road. The density is measured as the number of vehicles $\mathrm{N}$ that occupy a segment of a road of a length $\mathrm{L}$. The density equals $\mathrm{N}$ divided by $\mathrm{L}$, and its unit is expressed as Vehicles/Kilometer. The maximum allowable speed on the highway (in Indonesia) is $100 \mathrm{~km} / \mathrm{h}$ and the minimum speed is 60 $\mathrm{km} / \mathrm{h}$. But in fact, it depends on the condition of the traffic and the speed may be less or more than that. In this simulation, the speeds are set to $20 \mathrm{~km} / \mathrm{h}$ (low speed), $60 \mathrm{~km} / \mathrm{h}$ (medium speed) and $100 \mathrm{~km} / \mathrm{h}$ (high speed), with constant acceleration.

The work is undertaken according to three scenarios:

(1) Node speed at $20 \mathrm{kph}$ and various traffic densities

(2) Node speed at $60 \mathrm{kph}$ and various traffic densities

(3) Node speed at $100 \mathrm{kph}$ and various traffic densities

\section{Simulation Steps}

The simulation is carried out in four activities as follows. (1) Create a mobility model that will be implemented in the simulation using SUMO. (2) Input the results of the SUMO process, which consists of TCL file and mobility pattern file into network simulator NS2. The activity (1) and (2) are visually depicted in Fig. 4. (3) Configure the network parameters in NS2 suitable for the VANETs: The protocol (AODV or AOMDV), the numbers of the node, the size area and the node speed, then run NS2. (4) Analyze the performance of the model in terms of PDR, EED and Reliability based on the trace file as a result of running the NS2 simulator.

Table 2: Parameters of simulation

\begin{tabular}{ll}
\hline Parameter & Value \\
\hline Channel type & Wireless \\
Routing protocol & AODV, AOMDV \\
Traffic type & TCP \\
Time of simulation (s) & 9002 nds (15 min) \\
Queue length (byte) & 2048 \\
Dimensions (m) & $50 \times 5000$ \\
MAC protocol & $802.11 \mathrm{Ext}$ \\
Number of nodes (unit) & $50,100,150,200,250,300$ \\
Node speed (m/s) & $6,17,28(20,60,100 \mathrm{kph})$ \\
\hline
\end{tabular}




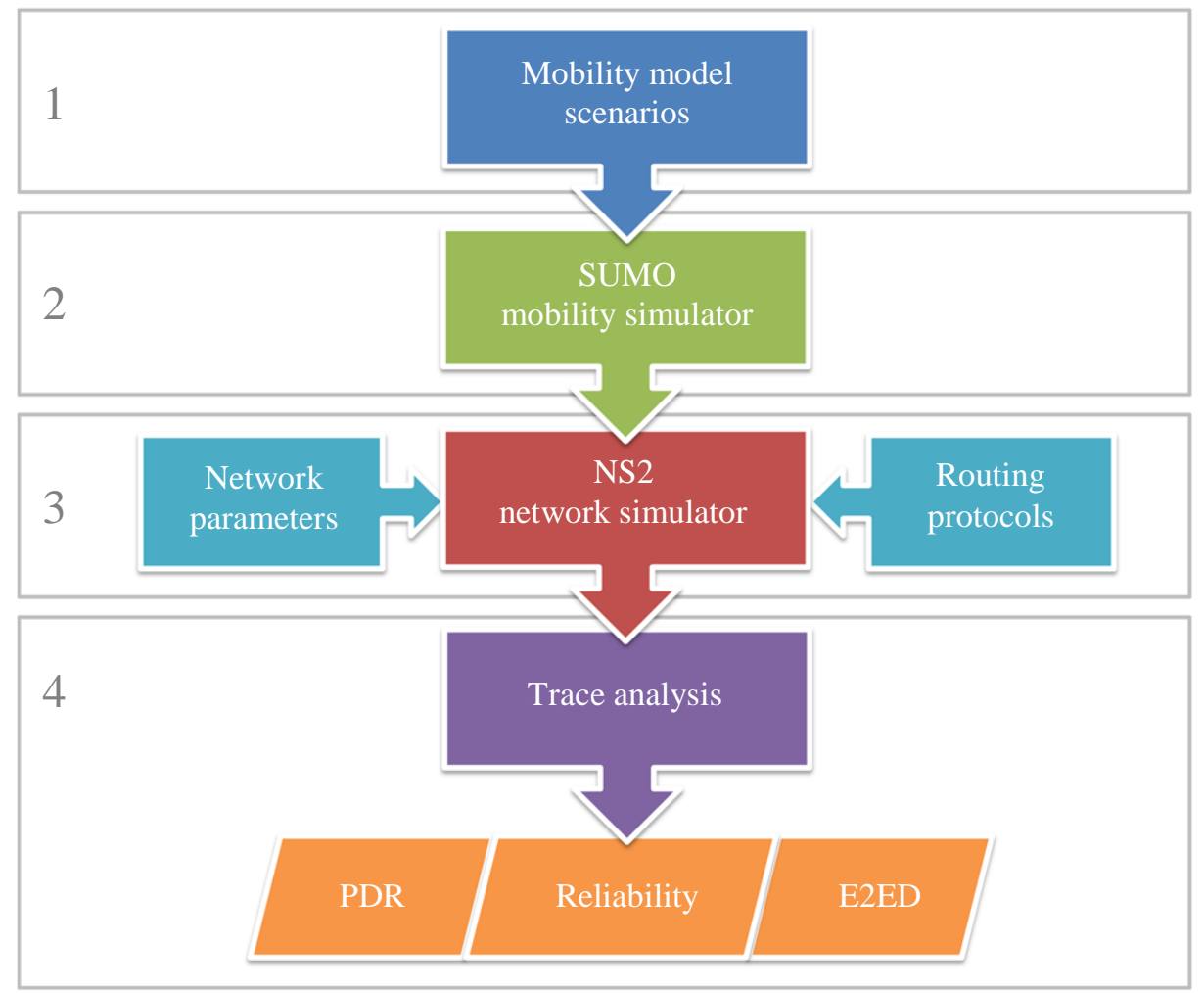

Fig. 3: Research methodology

\section{SUMO: Traffic mobility simulation}

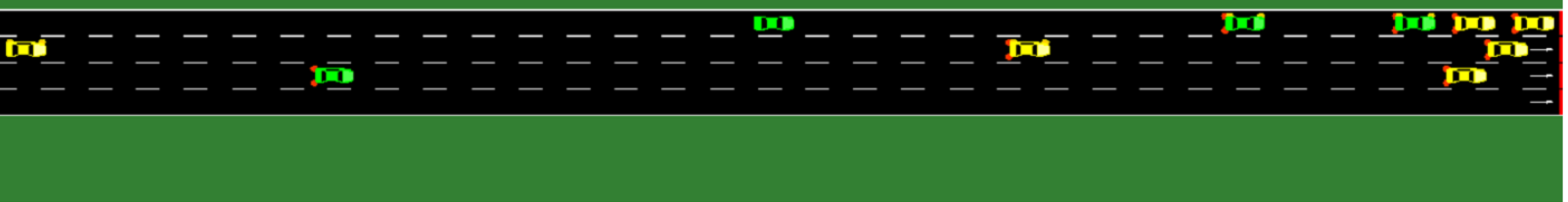

NS2: Network simulation
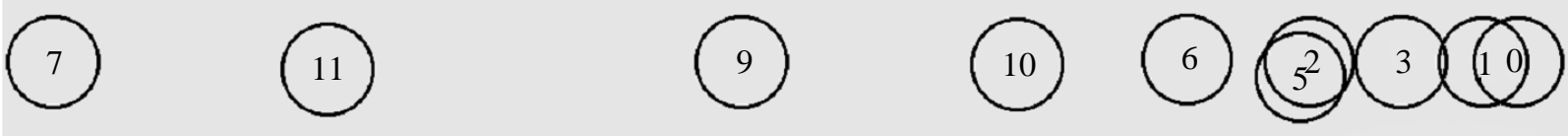

Fig. 4: Traffic and Network Simulation Using SUMO and NS2

\section{Results and Discussion}

The results of the simulations with various speeds of vehicles at $20 \mathrm{kph}, 60 \mathrm{kph}$ and $100 \mathrm{kph}$ and various densities are presented in Table 3 to 5, respectively. The contrastive graphs of the two routing protocols' performances in different conditions, Density and Speed, are depicted in Fig. 5 to 13, respectively. This study is focusing on three performance evaluations: Packet
Delivery Ratio (PDR), Average End-to-End Delay (AEED) and Reliability (R). Those three metrics determine whether the routing protocols are suitable for road safety applications or not. The requirements to justify the compliances of the routing protocols refer to Table 1 in the subsection above.

On each chart, we put lines as marks to facilitate us in determining which protocol and what condition fulfills the road safety application requirements. Line-1 
(99\%) on the Reliability charts indicates the minimum value of the reliability that meets the requirement. Only values above the line-1 are acceptable. Line-1 (99\%) on the PDR charts denotes the minimum value of the PDR that meets the requirement for "Pre-crash sensing" and "Cooperative platooning." Line-2 (95\%) on the PDR charts shows the minimum value of the PDR that meets the requirement for "Cooperative forward collision warning," "Wrong-way driving,"
"Approaching emergency vehicle warning," "Slow vehicle warning," "Post-crash warning," and "Traffic jam ahead warning." Line-1 (400 ms) on the EED charts ticks the maximum value of the EED that meets the requirement for "Slow vehicle warning," "Postcrash warning," and "Traffic jam ahead warning." Line-2 (200 ms) on the EED charts points to the maximum value of the EED that meets the requirement for "Approaching emergency vehicle warning.

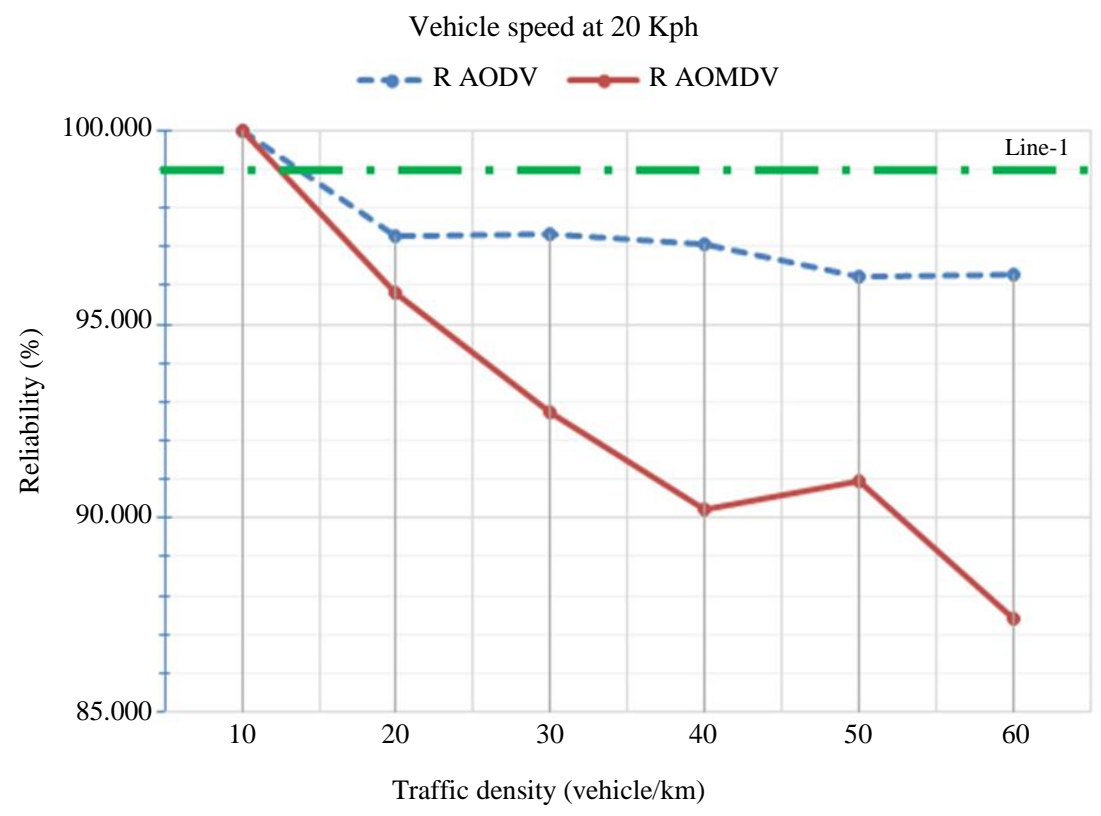

Fig. 5: Reliability of routing protocols at speed $20 \mathrm{kph}$

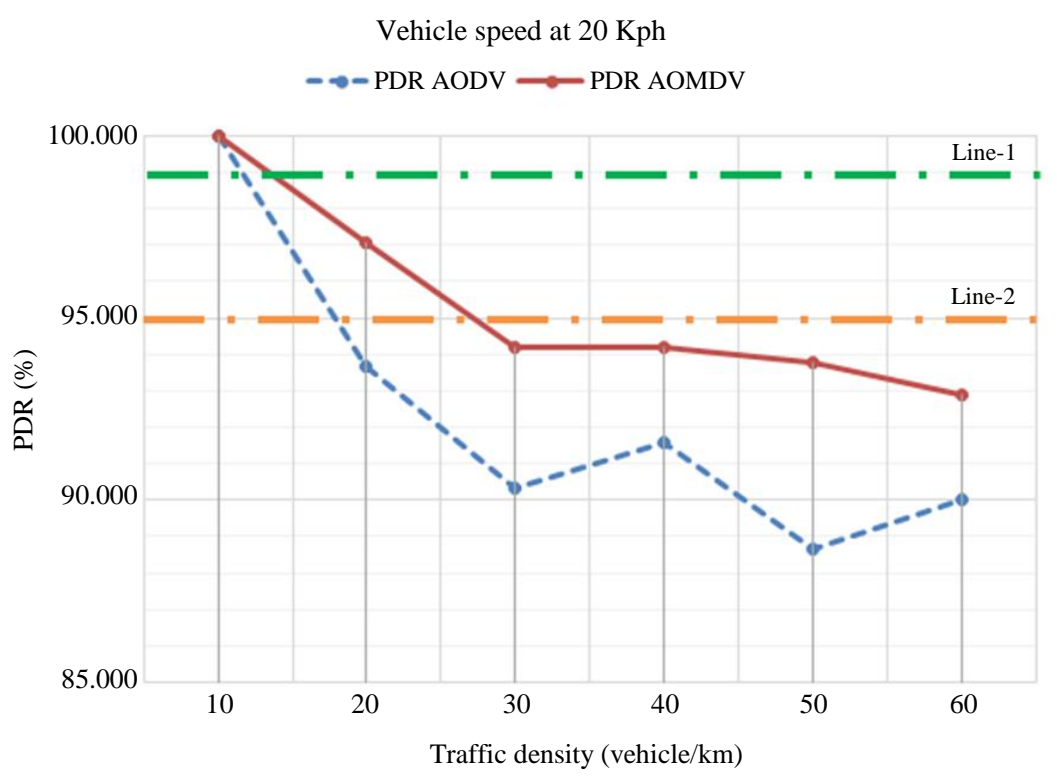

Fig. 6: PDR of routing protocols at speed $20 \mathrm{kph}$ 


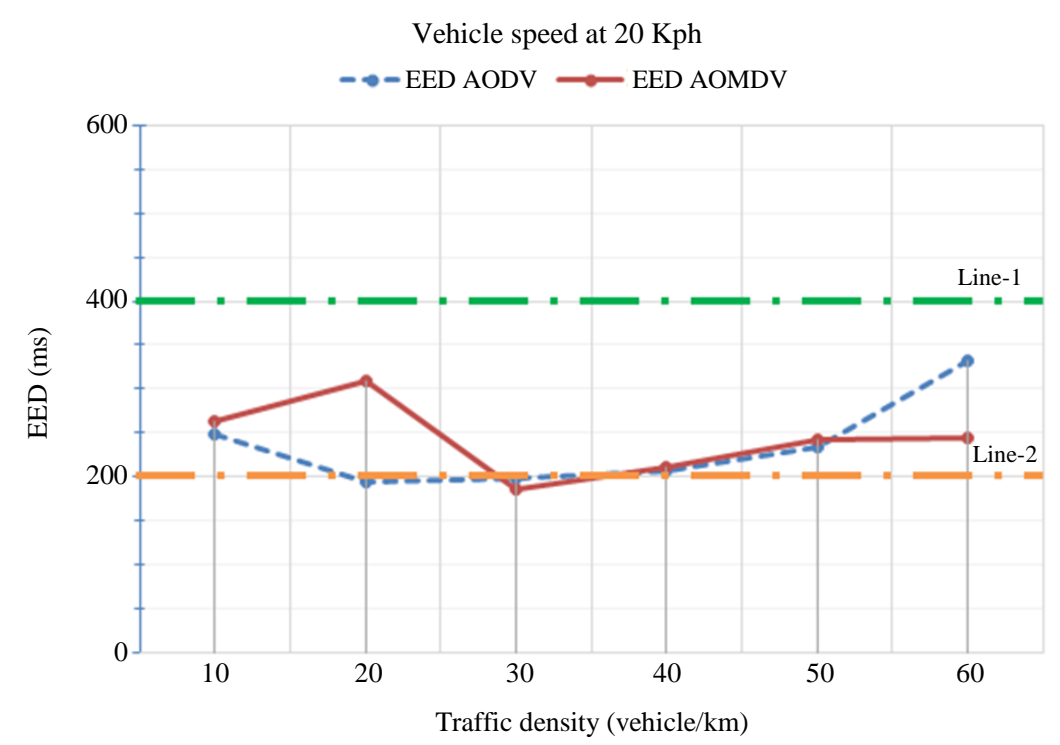

Fig. 7: Average EED of Routing Protocols at Speed $20 \mathrm{kph}$

Table 3: Routing protocol performance at speed $20 \mathrm{kph}$

\begin{tabular}{|c|c|c|c|c|c|c|}
\hline \multirow{2}{*}{$\begin{array}{l}\text { Density } \\
\text { (vehicle/km) }\end{array}$} & \multicolumn{2}{|c|}{ Reliability (\%) } & \multicolumn{2}{|c|}{ PDR $(\%)$} & \multicolumn{2}{|c|}{$\mathrm{EED}(\mathrm{ms})$} \\
\hline & AODV & AOMDV & AODV & AOMDV & AODV & AOMDV \\
\hline$\overline{10}$ & 99.992 & 99.994 & 99.969 & 99.972 & 248 & 263 \\
\hline 20 & 97.249 & 95.803 & 93.678 & 97.079 & 194 & 309 \\
\hline 30 & 97.308 & 92.712 & 90.307 & 94.178 & 198 & 186 \\
\hline 40 & 97.057 & 90.238 & 91.603 & 94.216 & 208 & 211 \\
\hline 50 & 96.232 & 90.972 & 88.674 & 93.788 & 234 & 242 \\
\hline 60 & 96.259 & 87.405 & 90.008 & 92.883 & 331 & 245 \\
\hline
\end{tabular}

Table 4: Routing protocol performance at speed $60 \mathrm{kph}$

\begin{tabular}{|c|c|c|c|c|c|c|}
\hline \multirow{2}{*}{$\begin{array}{l}\text { Density } \\
\text { (vehicle/km) }\end{array}$} & \multicolumn{2}{|c|}{ Reliability (\%) } & \multicolumn{2}{|c|}{ PDR (\%) } & \multicolumn{2}{|c|}{ EED (ms) } \\
\hline & AODV & AOMDV & AODV & AOMDV & AODV & AOMDV \\
\hline$\overline{10}$ & 99.185 & 99.258 & 97.634 & 99.387 & 335 & 133 \\
\hline 20 & 99.072 & 97.004 & 98.525 & 99.192 & 503 & 175 \\
\hline 30 & 99.103 & 97.392 & 99.225 & 99.203 & 374 & 218 \\
\hline 40 & 98.833 & 98.218 & 98.575 & 99.127 & 365 & 340 \\
\hline 50 & 97.961 & 97.061 & 96.815 & 96.725 & 246 & 399 \\
\hline 60 & 97.646 & 90.761 & 90.839 & 94.198 & 214 & 483 \\
\hline
\end{tabular}

Table 5: Routing protocol performance at speed $100 \mathrm{kph}$

\begin{tabular}{|c|c|c|c|c|c|c|}
\hline \multirow{2}{*}{$\begin{array}{l}\text { Density } \\
\text { (vehicle/km) }\end{array}$} & \multicolumn{2}{|c|}{ Reliability (\%) } & \multicolumn{2}{|c|}{ PDR (\%) } & \multicolumn{2}{|c|}{ EED (ms) } \\
\hline & AODV & AOMDV & AODV & AOMDV & AODV & AOMDV \\
\hline$\overline{10}$ & 99.770 & 99.797 & 99.895 & 99.875 & 120 & 130 \\
\hline 20 & 99.570 & 99.552 & 99.480 & 99.788 & 396 & 182 \\
\hline 30 & 99.310 & 99.262 & 98.958 & 98.843 & 374 & 304 \\
\hline 40 & 99.294 & 98.996 & 98.735 & 98.070 & 360 & 393 \\
\hline 50 & 99.656 & 90.693 & 99.364 & 98.918 & 247 & 517 \\
\hline 60 & 97.843 & 91.409 & 91.294 & 92.315 & 203 & 255 \\
\hline
\end{tabular}

\section{Performance at Speed $20 \mathrm{kph}$}

The performance of the protocols at a vehicle speed of $20 \mathrm{kph}$ in terms of reliability, packet delivery ratio (PDR) and Average End to End Delay (average EED) are shown in Fig. 5 to 7, respectively.

\section{Reliability}

Figure 5 shows that both AODV and AOMDV fulfill the reliability requirement of the road safety applications only in density ten since their reliabilities are above 99\%. The reliability of both protocols 
decreases when the number of nodes is getting bigger. For density from 20 to 60, AODV drops a little bit and is still over 96\%, whereas, AOMDV falls very steep until $87 \%$ at density 60. In general, the AODV reliability is better than AOMDV in density 10 to 60 with speed $20 \mathrm{kph}$.

\section{Packet Delivery Ratio (PDR)}

Figure 6 shows the PDR of the protocols when the vehicle speed is $20 \mathrm{kph}$. In a density of 10, the protocols'
PDR is higher than 99\%, and it means that AODV and AOMDV meet the requirement of the road safety applications. In the density of 20, AOMDV has value over $95 \%$, which still meets the requirement of some applications, but not for AODV. For the density from 30 to 60 , none of the protocols achieves the minimum PDR required for the applications. As we can see, AOMDV performs better than AODV in terms of PDR in density 10 to 60 for the speed of $20 \mathrm{kph}$.

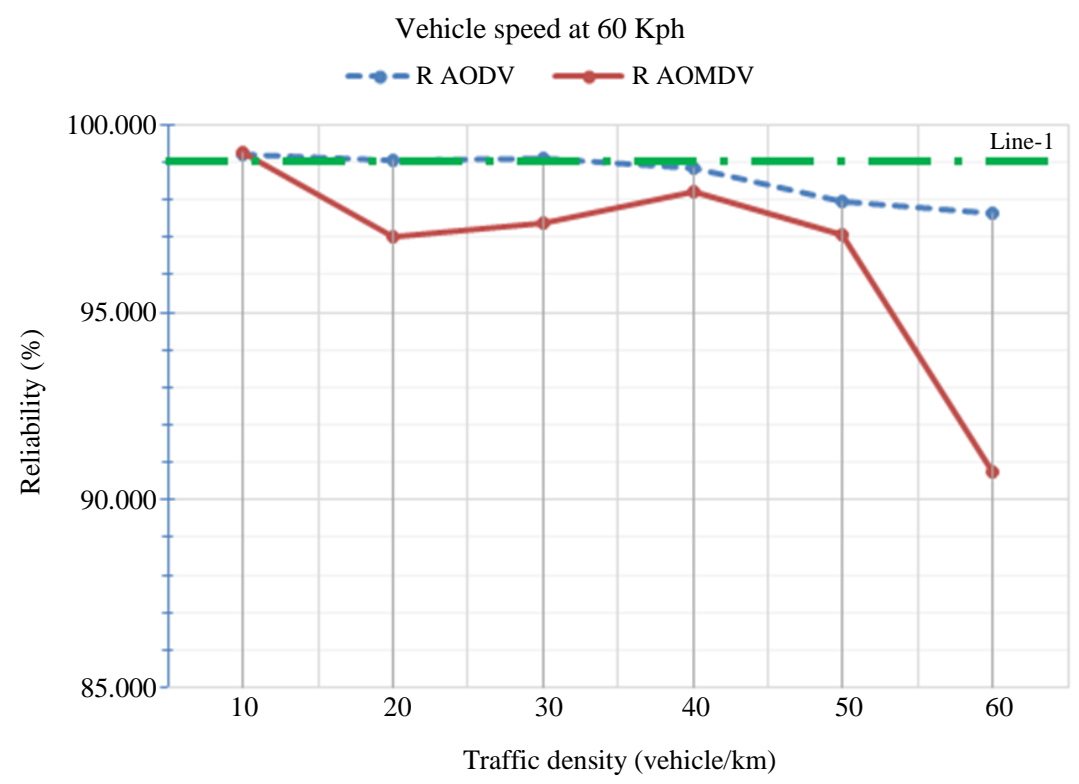

Fig. 8: Reliability of routing protocols at speed $60 \mathrm{kph}$

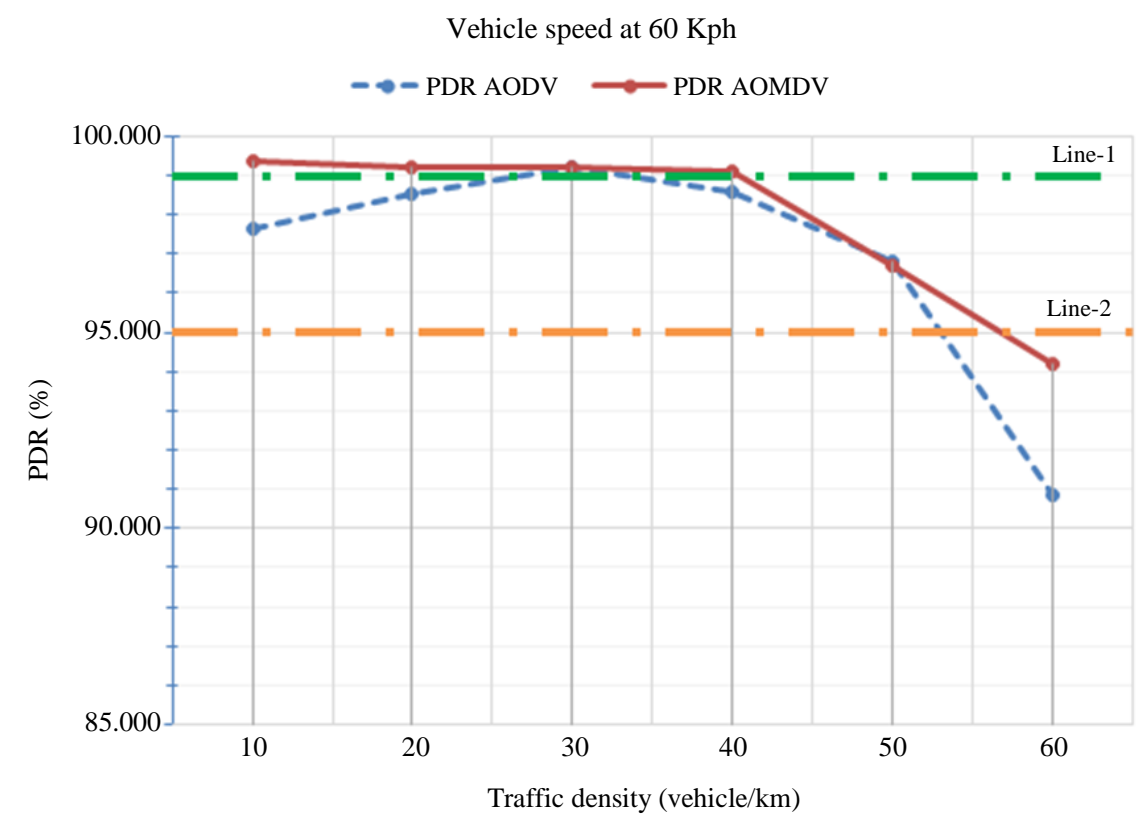

Fig. 9: PDR of routing protocols at speed $60 \mathrm{kph}$ 


\section{Average End-to-End Delay}

Figure 7 represents the average EED of the protocols when the vehicle speed is $20 \mathrm{kph}$. The average EED of the protocols in all density values is under maximum value, which is $400 \mathrm{~ms}$. In density 20 and 30, AODV has average EED under $200 \mathrm{~ms}$; otherwise, AOMDV only in density 30 has an average EED under $200 \mathrm{~ms}$.

Based on the performance results above and application requirements, we can conclude that for the speed of $20 \mathrm{kph}$ when the density is 10 , the routing protocol AODV and AOMDV are suitable for "Slow vehicle warning," "Post-crash warning," and "Traffic jam ahead warning."

\section{Performance at Speed $60 \mathrm{kph}$}

The performance of the protocols at a vehicle speed of $60 \mathrm{kph}$ in terms of reliability, Packet Delivery Ratio (PDR) and the average End to End Delay (average EED) are presented in Fig. 8 to 10, respectively.

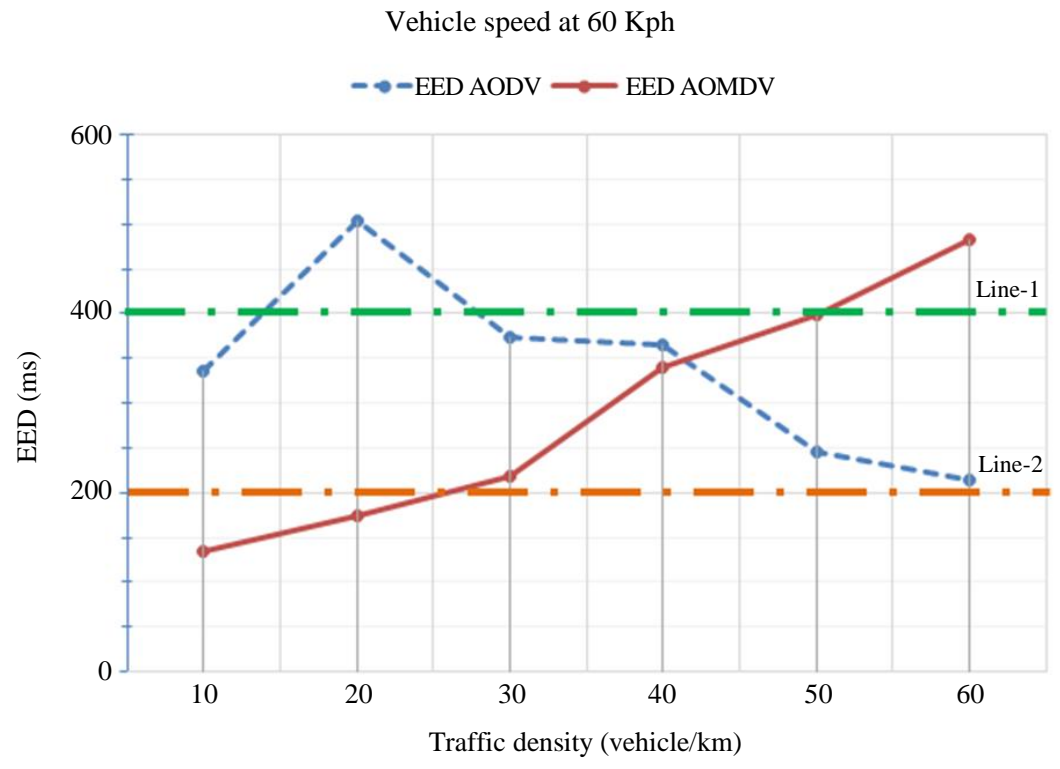

Fig. 10: Average EED of routing protocols at speed $60 \mathrm{kph}$

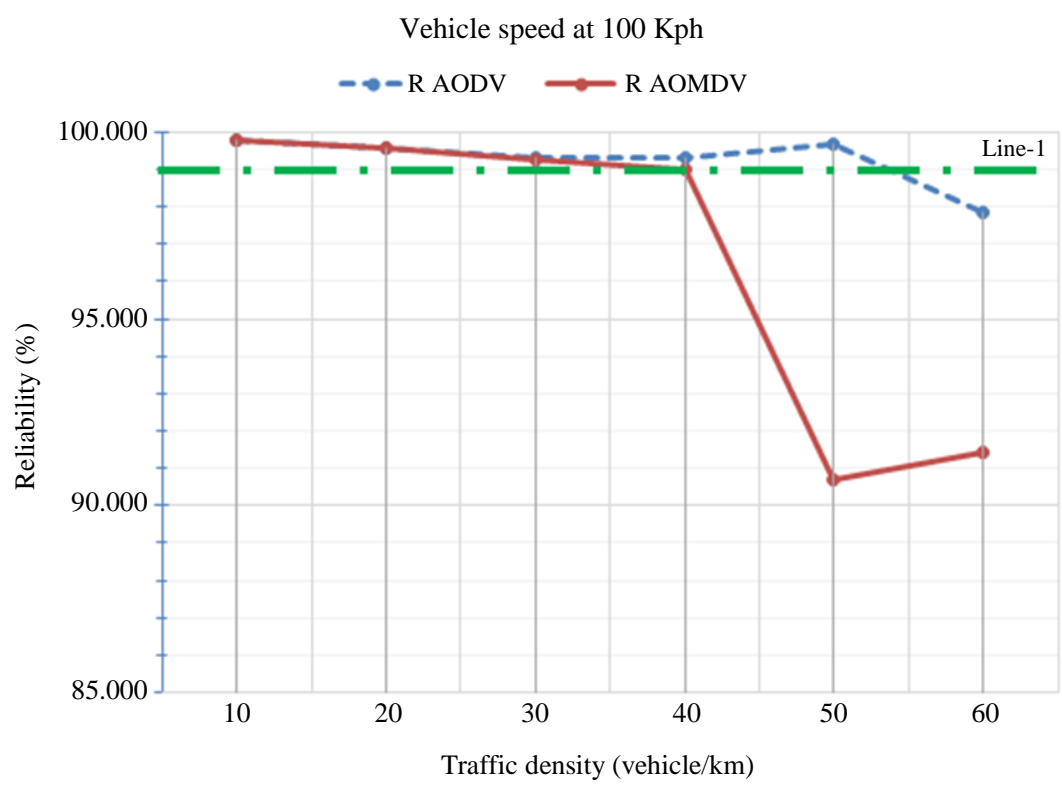

Fig. 11: Reliability of routing protocols at speed $100 \mathrm{kph}$ 


\section{Reliability}

Figure 8 shows that the reliability of AODV for density 10, 20 and 30 are above $99 \%$ so that they meet the requirement, even though they fall under the minimum value for density 40 to 60 . On the other hand, AOMDV reliability is excellent just in density 10 and falls quite a lot up to $91 \%$ at density 60 . The reliability of both protocols decreases when the number of vehicles increases. We can say that the AODV reliability is better than AOMDV in density 10 to 60 at the vehicle speed of $60 \mathrm{kph}$.

\section{Packet Delivery Ratio (PDR)}

Figure 9 depicts the protocols' PDR when the vehicle speed is $60 \mathrm{kph}$. In density 10 to 50 , the PDR of both protocols, AODV and AOMDV, are higher than 95\%, it means that AODV and AOMDV meet the requirement of the road safety applications. Also, in density 10 to 40 , AOMDV has a value of over $99 \%$, which is very good, but not for AODV. For density 60, none of the protocols achieves the minimum PDR required for the applications. As we observe, AODV and AOMDV perform quite similar in terms of PDR in density 10 to 60 for the speed of $60 \mathrm{kph}$.

\section{Average End-to-End Delay}

Figure 10 represents the average EED of the protocols when the vehicle speed is $60 \mathrm{kph}$. The average EED of AODV in density 10, 30, 40, 50 and 60 are under maximum value $400 \mathrm{~ms}$, which are met the requirement, except in density 20, it's above $400 \mathrm{~ms}$. The AOMDV performs well in density 20 to 50 in terms of average EED and indeed in density 10 and 20, it is under $200 \mathrm{~ms}$. But not in density 60, AOMDV's EED is $483 \mathrm{~ms}$, over the maximum threshold. At $60 \mathrm{kph}$ vehicle's speed, by increasing the density, AMODV tends to have higher EED while AODV vice versa.

Based on the performance results above and application requirements, we can deduce that for the speed of $60 \mathrm{kph}$, the routing protocol AOMDV is suitable for "Approaching emergency vehicle warning," "Slow vehicle warning," "Post-crash warning," and "Traffic jam ahead warning" when the density is 10 . The AODV is suitable for "Slow vehicle warning," "Postcrash warning," and "Traffic jam ahead warning" in density 10 and 30.

\section{Performance at Speed $100 \mathrm{kph}$}

The performance of the protocols at a vehicle speed of $100 \mathrm{kph}$ in terms of reliability, packet delivery ratio (PDR) and the average end to end delay (average EED) are shown in Fig. 11 to 13, respectively.

\section{Reliability}

Figure 11 presents the reliability of both AODV and AOMDV at $100 \mathrm{kph}$ vehicle's speed. It tells that the reliability of AODV is more than $99 \%$ in density 10 to 50 , whereas under $99 \%$ in density 60 . The reliability of AOMDV in density 10, 20 and 30 is more excellent than $99 \%$ and then drops under $99 \%$ in density 40 to 60 . In other words, AODV meets the road safety application requirement in density 10 to 50 and $A O M D V$ in 10 to 30. In general, the AODV reliability is better than AOMDV in density 10 to 60 at speed $100 \mathrm{kph}$.

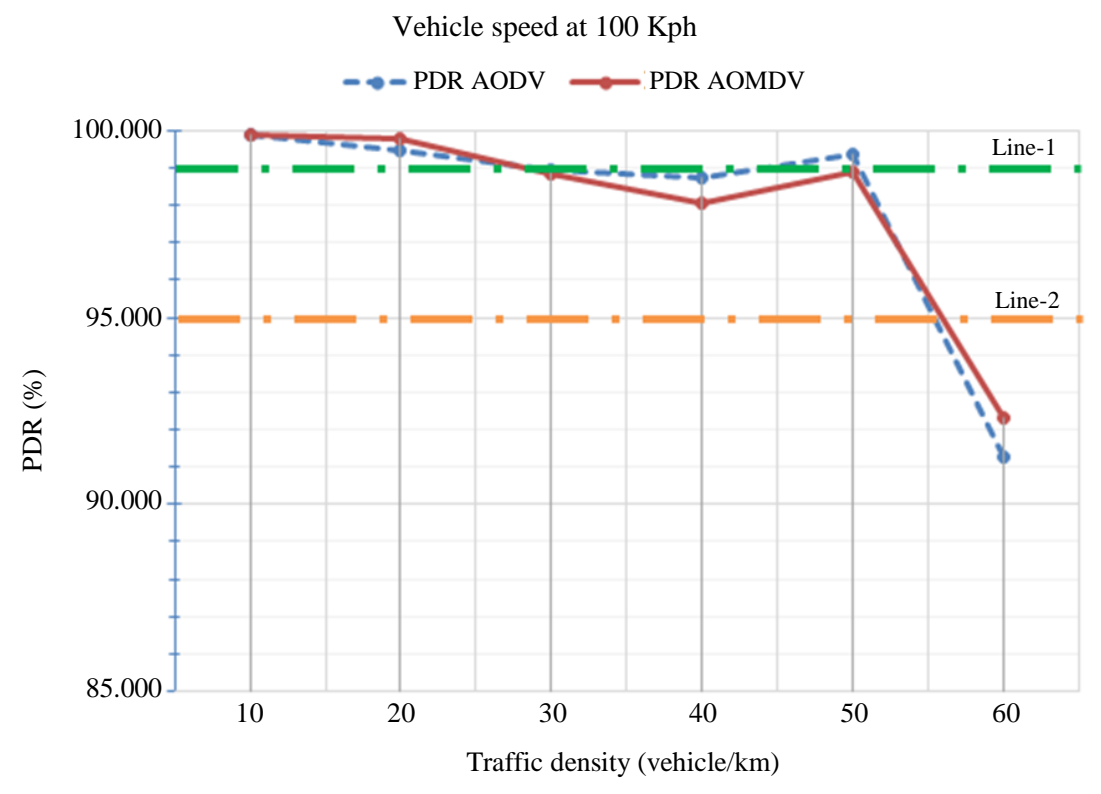

Fig. 12: PDR of routing protocols at speed $100 \mathrm{kph}$ 


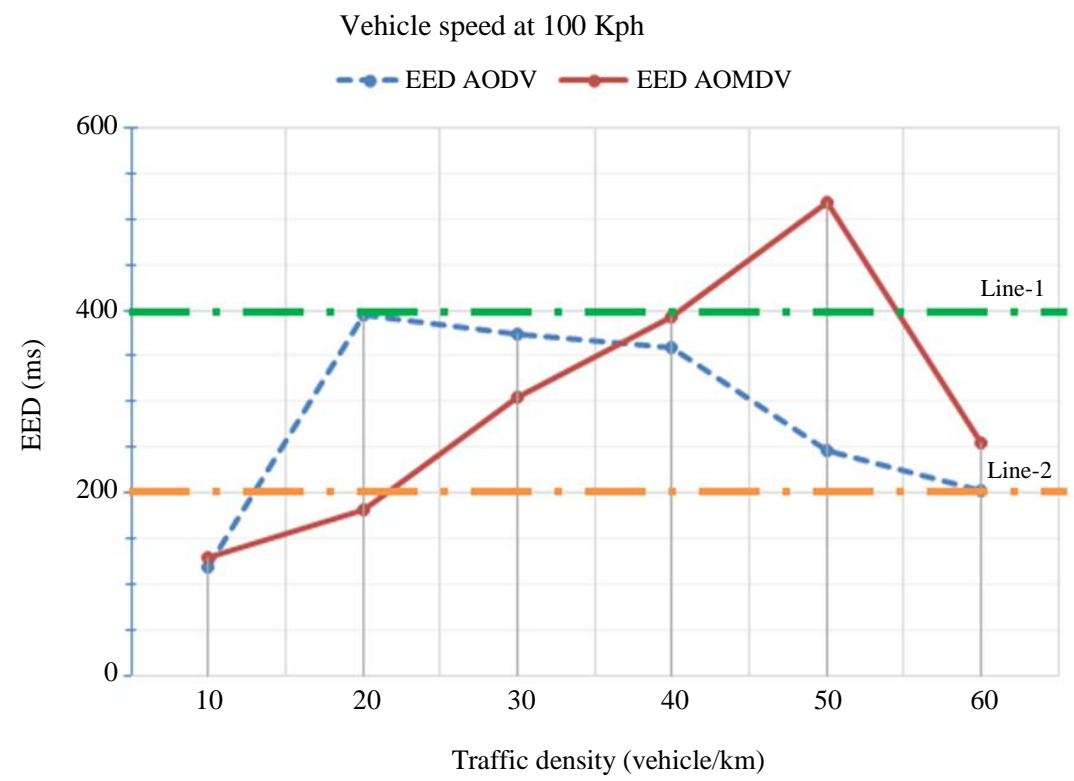

Fig. 13: Average EED of Routing Protocols at Speed $100 \mathrm{kph}$

\section{Packet Delivery Ratio (PDR)}

Figure 12 represents the protocols' PDR when the vehicle speed is $100 \mathrm{kph}$. In density 10 to 50 , the PDR of both protocols, AODV and AOMDV, are higher than $95 \%$, it means that AODV and AOMDV meet the requirement of the road safety applications in those densities. Furthermore, in density 10 and 20, both protocols reach a great PDR value of over $99 \%$. In density 60 , both protocols' PDR falls under $95 \%$. As we observe, AODV and AOMDV tend to perform almost the same in terms of PDR in density 10 to 60 for the speed of $100 \mathrm{kph}$.

\section{Average End-to-End Delay}

Figure 13 shows the average EED of the protocols when the vehicle speed is $100 \mathrm{kph}$. The average EED of the AODV protocol in all densities is under the maximum value of $400 \mathrm{~ms}$. Indeed in density 10, AODV has average EED under $200 \mathrm{~ms}$. The AOMDV protocol, except in density 50, has average EED under $400 \mathrm{~ms}$ and in density 10 to 20 under $200 \mathrm{~ms}$.

Based on the performance results above and application requirements, we can recapitulate that for the speed of $100 \mathrm{kph}$, the routing protocol AOMDV is suitable for "Slow vehicle warning," "Post-crash warning," and "Traffic jam ahead warning" when the density is 10,20 and 30; and with the addition "Approaching emergency vehicle warning" in density 10 and 20 . The AODV is suitable for "Slow vehicle warning," "Post-crash warning," and "Traffic jam ahead warning" in density 10 to 50 and with the addition "Approaching emergency vehicle warning" in density 10 .

\section{Conclusion}

We have researched in investigating the quantitative measure of the reliability of reactive singe-path and multi-path routing protocols that comply with road safety requirements in various traffic conditions for autonomous cars. The traffic conditions (node density and speed of the nodes) have impacted the performance of VANET-based autonomous cars in terms of PDR, EED and Reliability, as shown in the results.

In this study, the performance comparison of two reactive routing protocols, AODV and AOMDV, for three performance evaluations in three different vehicle speeds has been conducted. This work reveals that the bigger the density and the speed of the nodes, the lower the PDR, the EED and the Reliability. Also, we found out that the road safety application requirements of the routing protocols in compliance with PDR, EED and Reliability can be fulfilled in specific terms and conditions where density is not too crowded and the speed is not too slow. By knowing these results, we come up with recommendations in applying the routing protocols for road safety applications. First, in choosing a single-path or a multi-path routing protocol, we need to consider which road safety application will be sent and what the traffic conditions are so that the message will be received by destination successfully and reliably. Second, since the existing routing protocols have limitations in coping with the number of nodes and the vehicle speed, it would be wiser to use them under boundaries that still meet the requirements.

In future work, we attempt to enhance the existing reactive multi-path protocol AOMDV drawback by improving the algorithm on the routing process. Also, we 
will refine the methods and strategies so that the new enhanced routing protocol can overcome the weaknesses.

\section{Acknowledgement}

The authors would like to thank members of the research team for their contribution and resources in this study. The first author also wishes to thank friends of DIK-UI 2016 for their motivation and encouragement.

\section{Funding Information}

This research is funded by "Direktorat Riset dan Pengembangan Universitas Indonesia (Risbang UI)" entitled "Hibah Riset UI 2020 dengan skema Publikasi Terindeks Internasional Doktor (PUTI Doktor 2020)" Nomor: NKB-565/UN2.RST/HKP.05.00/2020.

\section{Author's Contributions}

Ananto Tri Sasongko: Selected the topic and analyzed the literature along with proposing and implementing the methods, also conducting the simulation experiments.

Wisnu Jatmiko: Supervised the research by reviewing the manuscript iteratively, provided encouraging suggestions and recommendations.

Bob Hardian: Contributed to the manuscript review, discussed the research and gave constructive comments.

Grafika Jati: Assisted in preparing the simulation and discussed the content of the paper intensively.

\section{Ethics}

The participants are informed that their comments will contribute to a research project and all other authors have read and approved the manuscript and no ethical problem.

\section{References}

Abdel-Halim, I.T. and H.M.A. Fahmy, 2018. Predictionbased protocols for vehicular Ad Hoc Networks: Survey and taxonomy. Comput. Networks, 130: 34-50. DOI: 10.1016/J.COMNET.2017.10.009

Agresti, A. and B.A. Coull, 1998. Approximate is better than "Exact" for interval estimation of binomial proportions. Am. Stat., 52: 119-126.

DOI: 10.1080/00031305.1998.10480550

Al-Sultan, S., M.M. Al-Doori, A.H. Al-Bayatti and H. Zedan, 2014. A comprehensive survey on vehicular Ad Hoc network. J. Network Comput. Applic., 37: 380-392. DOI: 10.1016/J.JNCA.2013.02.036

Aravindhan, K. and C.S.G. Dhas, 2019. Destinationaware context-based routing protocol with hybrid soft computing cluster algorithm for VANET. Soft Comput., 23: 2499-2507.

DOI: $10.1007 / \mathrm{S} 00500-018-03685-7$
Arif, M., G. Wang, M. Zakirul Alam Bhuiyan, T. Wang and J. Chen, 2019. A survey on security attacks in VANETs: Communication, applications and challenges. Vehicular Commun., 19: 1-36. DOI: 10.1016/J.VEHCOM.2019.100179

Bello-Salau, H., A.M. Aibinu, Z. Wang, A.J. Onumanyi and E.N. Onwuka et al., 2019. An optimized routing algorithm for vehicle ad-hoc networks. Eng. Sci. Technol. Int. J., 22: 754-766. DOI: 10.1016/J.JESTCH.2019.01.016

Birolini, A., 2017. Reliability Engineering: Theory and Practice. 4th Edn., Springer Science and Business Media, ISBN-10: 3662054094, pp: 544.

Brown, L.D., T.T. Cai and A. DasGupta, 2001. Interval estimation for a binomial proportion. Stat. Sci., 16: 101-117. DOI: 10.1214/ss/1009213286

Cunha, F., L. Villas, A. Boukerche, G. Maia and A. Viana et al., 2016. Data communication in VANETs: Protocols, applications and challenges. Ad Hoc Networks, 44: 90-103. DOI: 10.1016/J.ADHOC.2016.02.017

Darwish, T.S.J., K. Abu Bakar and K. Haseeb, 2018. Reliable intersection-based traffic aware routing protocol for urban areas vehicular ad hoc networks. IEEE Intell. Trans. Syst. Magazine, 10: 60-73. DOI: 10.1109/MITS.2017.2776161

Franco, C., R.J.A. Little, T.A. Louis and E.V. Slud, 2019. Comparative study of confidence intervals for proportions in complex sample surveys $\uparrow$. J. Survey Stat. Methodol., 7: 334-364. DOI: $10.1093 / \mathrm{JSSAM} / \mathrm{SMY} 019$

Herlich, M., T. Pfeiffenberger, J. Du and P. Dorfinger, 2017. 5G-MLab: Developing a wireless reliability measurement framework. Proceedings of the Wireless Congress: Systems and Applications, (CSA’17), Munich, pp: 1-7.

Houmer, M. and M.L. Hasnaoui, 2019. A qualitative assessment of VANET routing protocols under different mobility models. J. Comput. Sci., 15: 161-170. DOI: $10.3844 /$ jcssp.2019.161.170

Hussain, R. and S. Zeadally, 2019. Autonomous cars: Research results, issues and future challenges. IEEE Commun. Surveys Tutorials, 21: 1275-1313. DOI: 10.1109/COMST.2018.2869360

Kuhr, J., 2017. D-STOP symposium.

Marina, M.K. and S.R. Das, 2006. Ad hoc on-demand multipath distance vector routing. Wireless Commun. Mobile Comput., 6: 969-988. DOI: $10.1002 / W C M .432$

Peng, H., L. Liang, X. Shen and G.Y. Li, 2019. Vehicular communications: A network layer perspective. IEEE Trans. Vehicular Technol., 68: 1064-1078. DOI: 10.1109/TVT.2018.2833427 
Perkins, C.E. and E.M. Royer, 1999. Ad-hoc on-demand distance vector routing. Proceedings of the 2nd Workshop on Mobile Computing Systems and Applications, Feb. 25-26, IEEE Xplore Press, New Orleans, LA, USA, pp: 90-100.

DOI: 10.1109/MCSA.1999.749281

Popescu-Zeletin, R., I. Radusch and A.M. Rigani, 2010. Vehicular-2-X Communication: State-of-the-Art and Research in Mobile Vehicular Ad hoc Networks. 1st Edn., Springer Science and Business Media, ISBN-10: 3540771433, pp: 112.

Ros, F.J., J.A. Martinez and P.M. Ruiz, 2014. A survey on modeling and simulation of vehicular networks: Communications, mobility and tools. Comput. Commun., 43: 1-15. DOI: 10.1016/J.COMCOM.2014.01.010

Saajid, H., W. Di, X. Wang, S. Memon and N.K. Bux et al., 2019. Reliability and connectivity analysis of vehicular ad hoc networks under various protocols using a simple heuristic approach. IEEE Access, 7: 132374-132383.

DOI: 10.1109/ACCESS.2019.2940872

Sahoo, J., E.H.K. Wu, P.K. Sahu and M. Gerla, 2013. Congestion-controlled-coordinator-based mac for safety-critical message transmission in VANETs. IEEE Trans. Intell. Trans. Syst., 14: 1423-1437. DOI: $10.1109 /$ TITS.2013.2264320
Salvo, P., F. Cuomo, A. Baiocchi and I. Rubin, 2015. Investigating VANET dissemination protocols performance under high throughput conditions. Vehicular Commun., 2: 185-194. DOI: 10.1016/J.VEHCOM.2015.07.003

Sathya Narayanan, P. and C.S. Joice, 2019. Vehicle-toVehicle (V2V) communication using routing protocols: A review. Proceedings of the 6th International Conference on Smart Structures and Systems, Mar. 14-15, IEEE Xplore Press, Chennai, India, pp: 1-10. DOI: 10.1109/ICSSS.2019.8882828

Sattar, S., H.K. Qureshi, M. Saleem, S. Mumtaz and J. Rodriguez, 2018. Reliability and energy- efficiency analysis of safety message broadcast in VANETs. Comput. Commun., 119: 118-126. DOI: 10.1016/j.comcom.2018.01.006

Yang, H. and Z. Liu, 2019. An optimization routing protocol for FANETs. Eurasip J. Wireless Commun. Network.

Zekri, A. and W. Jia, 2018. Heterogeneous vehicular communications: A comprehensive study. Ad Hoc Networks, 75-76: 52-79.

DOI: 10.1016/J.ADHOC.2018.03.010 